\title{
DIAGNOSTICS OF THE STRENGTH AND STIFFNESS OF THE LOADER CARRIER SYSTEM STRUCTURAL ELEMENTS IN TERMS OF THINNING OF WALLS BY NUMERICAL METHODS
}

\author{
Viktor OROBEY ${ }^{1}$, Oleksii NEMCHUK ${ }^{2}$, Oleksandr LYMARENKO ${ }^{1}$, Varvara PITERSKA ${ }^{2}$, \\ Olha SHERSTIUK ${ }^{2}$, Oleksandr ROMANOV ${ }^{1}$, Kateryna TKACHUK ${ }^{3}$ \\ ${ }^{1}$ Odessa Polytechnic State University, Ukraine \\ ${ }^{2}$ Odessa National Maritime University, Ukraine, e-mail: varuwa@ukr.net \\ ${ }^{3}$ Pryazovskyi State Technical University
}

\begin{abstract}
Modern gantry cranes are an indispensable element of large industrial and transport enterprises. Port handling equipment is operated under conditions of complex spatial loading of varying intensity, as well as under conditions when the walls of structural elements are thinned in the crane carrier system. During the operation of handling equipment in ports, at construction sites, in machine-building industries, in addition to the external load, aggressive media act on the carrier system elements, which leads to various types of wear: corrosive, abrasive and mechanical. Monitoring of the state of handling equipment structures is a very important task of diagnosing the state of the material of elements of the carrier system of cranes and transporting machines. An important and urgent scientific and technical problem of taking into account the influence of aggressive environment on the stress-strain state of the metal structures of gantry cranes is considered. It is noted that during corrosion, a significant thinning of the walls of structural elements occurs. The safety of crane operation requires this factor to be taken into account. It is proposed to use modern numerical methods for this, i.e. the boundary element method (BEM) and the finite element method (FEM). The implementation of these methods is performed in the Matlab programming and modeling environment (BEM), and the FEM is used in the Ansys package. In accordance with the technologies of these methods, the design diagrams of the lower girders and the crane structure as a whole were formed. Exact models of strain of crane elements during transverse bending and constrained torsion are given. Calculations of the stressstrain state of the crane metal structures have been performed. On the basis of a preliminary field study, a numerical model is proposed for diagnosing the strength and stiffness characteristics of the carrier system of handling equipment using the BEM and FEM, which has never been used in the world. Conclusions are drawn about the influence of the thinning of the walls of metal structures on the values of normal and tangential stresses.
\end{abstract}

Keywords: gantry cranes, boundary and finite element methods, stress-strain state, Matlab, Ansys

\section{INTRODUCTION}

Modern gantry cranes are an indispensable element of large industrial and transport enterprises. Port handling equipment is operated under conditions of complex spatial loads of varying intensity, as well as under conditions when the walls of structural elements are thinned in the crane carrier system. During the operation of handling equipment in ports, at construction sites, in machine-building industries, in addition to the external load, aggressive media act on carrier system elements, which leads to various types of wear: corrosive, abrasive and mechanical. As studies [1,2] show, the outer layers of the metal structure lose their mechanical properties and at the same time remain as a degrading component or are removed.

Based on a natural experiment and diagnostics of the state of the carrier system parts, it is possible to automate the monitoring of the strength and stiffness characteristics of the crane being researched.

The use of numerical methods for determining the stress-strain state of structural elements in terms of thinning of walls, is an urgent scientific task, and very important for the practice of operating handling equipment.

Among the available numerical methods, the finite element method, which is implemented in the science-intensive package Ansys, and the boundary element method, which is implemented in the Matlab programming and modeling environment, are selected, which is relevant in the study of complex technical problems.

\section{ANALYSIS OF RECENT RESEARCH AND PUBLICATIONS}

The work [1] is devoted to the study of structural elements of the crane carrier system, 
taking into account the decrease in wall thickness as a result of material degradation.

But the numerical analysis did not involve alternative calculation methods, which are the varieties of the boundary element method. In [2], the approach that provides for the calculation of the sensitivity of the stress-strain state components using finite-difference relations was proposed, but the verification of the results by a different "architecture" calculation method was not carried out. In the research [3], the finite element method and the full-scale experimental method were used, the issues of the presence of defects on the surface were considered, but the issues of changing the geometry of structure significant sections were not considered. The work [4] is devoted to computer modeling and strength analysis of engineering metal structures.

It should be noted that in [4], to study the strength of handling equipment structural elements, the thinning of the walls of structural elements was not taken into account.

The application of the finite element method (FEM) to the calculation of metal structures was considered in [5], however, only one calculation method and software package were involved in the research.

In [6], the calculation of the stress-strain state of the load lifting mechanism stand metal structure according to the limiting state was carried out using the finite element method.

It is shown that stresses act in all calculated areas, which do not lead to the accumulation of damage and their metal structures have unlimited durability, while alternative methods of the calculation were not involved in the research and the thinning of the walls of structural elements was not taken into account.

These works are devoted to the calculation of handling equipment for strength, but they do not consider the method of substructures using various numerical methods for diagnostics and analyzing the stress-strain state of structural elements.

In [7], the application of a numerical-analytical version of the boundary element method (BEM) to the calculation of the gantry crane rod elements is presented, but without taking into account the change in the thicknesses of the elements, and the calculation was performed for a flat design diagram, which is a simplification.

\section{THE PURPOSE OF THE RESEARCH}

The purpose of the research is to combine the use of field research, and numerical methods for determining the carrier system stress-strain state for diagnosing the handling equipment state and to provide the numerical study of the most accurate mathematical models of strain of both individual, most simple elements of cranes, and the entire structure as a whole, using the technology of modern numerical methods.
To achieve this goal, it is necessary to solve the following tasks:

1. To build design diagrams of the lower girders of the gantry and the entire crane structure in the BEM algorithm.

2. To determine the most dangerous types of resistance of the crane elements and form mathematical models of boundary value problems of the statics of the lower girders and the entire structure.

3. To carry out calculations of the stress-strain state of the gantry girders by the BEM in the Matlab programming environment.

4. To simulate the accepted design diagrams in the FEM package Ansys and carry out the corresponding calculations of the stress-strain state of structures.

5. To compare the results of calculations of crane structures by the BEM and FEM, to determine the dangerous spots of the crane metal structures and to formulate a conclusion about the state of the crane structure in terms of thinning of the walls.

\section{MATERIALS OF THE RESEARCH}

The crane PKP-30.5U1 (USSR, Leningrad) is under consideration. The metal structure of the crane has thin-wall box-type structural elements.

The state of the metal structure was determined by the visual and optical method and with the help of special devices for detecting defects and reducing the thickness of the metal, based on ultrasound (ultrasonic defectoscope, ultrasonic thickness gauge).

The inspection of the metal structure showed that, on the whole, the elements of the crane carrier system are in a satisfactory state, with the exception of the detected decrease in thickness in gantry girders.

The detected changes in thickness cause an increase in both stresses and strains. Under such conditions, the normal operation of the crane cannot be ensured, which means there is a danger to the working process.

Determination of the parameters of the stressstrain state of the crane carrier system or even individual structural elements with certain operational defects, damages and changes can be done analytically. However, the process of mathematical transformations turns out to be so complicated that all expediency of this solution is lost.

In these cases, the data of experimental studies and numerical calculation methods are used.

Most computer programs are based on the finite element method (FEM). It is known [7] that the use of the FEM has a number of disadvantages and can lead to distorted results even in the case of simple problems.

The most effective, among the alternative methods, is the boundary element method (BEM). 
In works [7-9], the modification of the BEM is proposed and developed, i.e. the numerical and analytical version of the boundary element method.

Based on the considered existing methods for determining the stress-strain state of structures [1015], the FEM and BEM are used.

\subsection{Formation of design diagrams of the gantry lower girder in the BEM}

The elements of gantry cranes are noted to have dangerous types of resistance, transverse bending and constrained torsion, and shear and tension can be neglected. As a result, the lower gantry girders, supported by stiffening ribs, can be represented by the following design diagram (Fig. 1) and external distributed load.
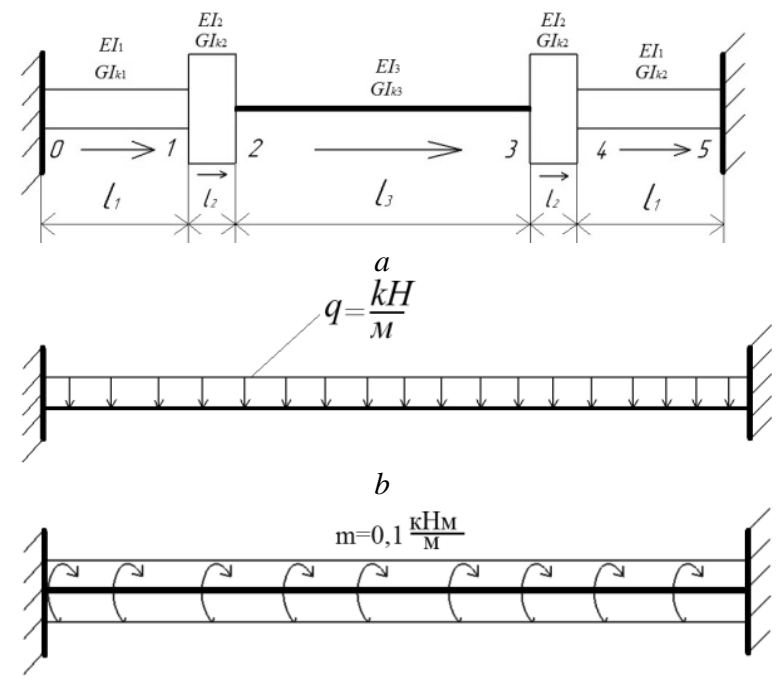

$c$

Fig. 1. Design diagram of the gantry lower girder: $a$ - sections with thinning; $b-$ distributed bending load; $c$-distributed torsional load

Thus, the modeling of the wall thinning process is reduced to design diagrams of the girder with different sections of stiffness and loaded with bending and torsional loads.

\subsection{Equation of the girder boundary value problem}

Since the section of the lower girder is a closed thin-walled rectangular profile with two axes of symmetry, the joint differential equation of bending and tangential torsion splits into two separate equations

transverse bending

$$
\sum_{i-1}^{n} \vartheta_{i}^{\prime \prime}(x)=\frac{q_{i}(x)}{E I_{i}}
$$

constrained torsion

$$
\sum_{i-1}^{n} \theta_{i}^{I V}(x)-k_{i}^{2} \theta_{i}^{I I}(x)=\frac{m_{i}(x)}{E I_{\omega i}},
$$

where $n$ is the number of girder sections with different stiffness; $\vartheta_{i}(x)$ is the transverse girder deflection on the $i$-th section, $\mathrm{m} ; q_{i}(x)$ is the transverse load, $\mathrm{kN} / \mathrm{m} ; E I_{i}-$ the bending section stiffness; $\theta_{i}(x)$ is the angle of the girder twisting on the $i$-th section, $\operatorname{rad} ; k_{i}^{2}=\frac{G I_{k i}}{E I_{\omega i}}$ is the bendingtorsion characteristic, $1 / \mathrm{m}^{2} ; m_{i}(x)$ is the torsional load, $\mathrm{kNm} / \mathrm{m} ; E I_{\omega i}$ is the sectorial stiffness of the section, $\mathrm{kNm}^{4}$. In the BEM algorithm, solutions of equations (1), (2) in the form of the method of initial parameters will appear in the matrix form (the indices $i$ are omitted) [1]:

under bending:

\begin{tabular}{|l|}
\hline$\vartheta(x)$ \\
\hline$\varphi(x)$ \\
\hline$M(x)$ \\
\hline$Q(x)$ \\
\hline
\end{tabular}$=$\begin{tabular}{|c|c|c|c|}
1 & 2 & 2 & 4 \\
\hline & & $-x / 2 E I$ & $-x^{3} / 6 E I$ \\
\hline & & 1 & $-x^{2} / 2 E I$ \\
\hline & & & $x$ \\
\hline
\end{tabular}

\begin{tabular}{|l|}
\hline$\vartheta(0)$ \\
\hline$\varphi(0)$ \\
\hline$M(0)$ \\
\hline$Q(0)$ \\
\hline$-B_{21}(x) / E I$ \\
\hline$-B_{31}(x)$ \\
\hline$-B_{41}(x) / E I$ \\
\hline
\end{tabular}

under constrained torsion:

\begin{tabular}{|c|}
\hline$\theta(x)$ \\
\hline$\theta^{\prime}(x)$ \\
\hline$B_{\omega}(x)$ \\
\hline$M_{\omega}(x)$ \\
\hline
\end{tabular} \mid \begin{tabular}{|c|c|c|c|c|}
\hline & $x$ & $-\frac{A_{13}}{G I_{k}}$ & & \\
\hline & 1 & $-\frac{A_{23}}{G I_{k}}$ & & \\
\hline & & $A_{33}$ & & $-\frac{A_{13}}{G I_{k}}$ \\
\hline & & $A_{23}$ & & $A_{34}$ \\
\hline
\end{tabular}

\begin{tabular}{|c|}
\hline$\theta(0)$ \\
\hline$\theta^{\prime}(0)$ \\
\hline$B_{\omega}(0)$ \\
\hline$M_{\omega}(0)$ \\
\hline \\
\hline
\end{tabular}

where $\varphi(\mathrm{x}), \varphi(0)$ is the angular section deflection at the current and initial points, rad; $M(\mathrm{x}), M(0)$ are bending moments, $k N m ; Q(\mathrm{x}), Q(0)$ are transverse forces, $k N ; \theta^{\prime}(\mathrm{x}), \theta^{\prime}(0)$ are derivatives of the girder twist angle at the current and initial points, rad; $B_{\omega}(\mathrm{x}), B_{\omega}(0)$ are bimoments, $k N m^{2} ; M_{\omega}(\mathrm{x}), M_{\omega}(0)$ are bending torques, $k N m$.

The elements of the bending load matrix according to Fig. 1 have the form:

$$
\begin{gathered}
B_{11}(x)=q x^{2} / 24 ; B_{21}(x)=q x^{3} / 6 ; \\
B_{31}(x)=q x^{2} / 2 ; B_{41}(x)=q x,
\end{gathered}
$$

the same when twisting:

$$
\begin{gathered}
B_{11}(x)=m\left\{[\operatorname{ch}(k x)-1] / k^{2}-x^{2} / 2\right\} ; \\
B_{21}(x)=m[\operatorname{sh}(k x) / k-x] ; \\
B_{31}(x)=m\left[\operatorname{ch}(k x)-1 / k^{2} ;\right] \\
B_{41}(x)=m s h(k x) / k .
\end{gathered}
$$

Fundamental orthonormal functions of equation 
(4) will be written in the form:

$$
\begin{gathered}
A_{13}=\operatorname{ch}(k x)-1 ; A_{13}=[\operatorname{sh}(k x)-k x] / k ; \\
A_{23}=k s h(k x) ; A_{33}=\operatorname{ch}(k x) ; A_{34}=\operatorname{sh}(k x) / k
\end{gathered}
$$

According to the design diagram (Fig. 1), the girder body has stepped stiffness. Such a case can be described analytically exactly in the BEM algorithm.

The formation of the resolving system of equations of the girder is performed step by step (separately for bending and torsion).

1. The nodes of the girder are numbered and the beginning and end of each section are marked with arrows (Fig.1), i.e. the girder is discretized into 5 sections. At each site, their lengths and stiffnesses are known.

2. The matrix of the initial parameters of the discretized girder $\mathbf{X}$, the matrix of the final parameters $\mathbf{Y}$ and the matrix of the external load B are formed. Solutions (3), (4) contain 4 equations, since the girder is divided into 5 sections, then the resolving equations of bending and torsion will have 20 final equations. Here you can take into account the symmetry of the boundary conditions and the girder design diagram. In this case, it is sufficient to consider only half of the design diagram. The number of sections will be reduced to 3 and the sizes of the resolving matrices will be reduced to 12 equations. Note that in the middle of the girder, the skewsymmetric parameters of bending and torsion will be equal to zero.

The matrices of the bending and load parameters will take the form:

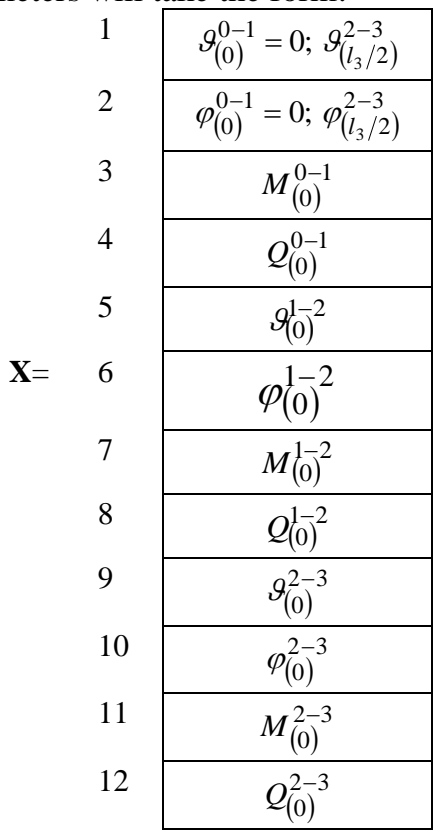

$$
\begin{aligned}
& \begin{array}{l|l|}
\cline { 2 - 2 } 2 & \vartheta_{\left(l_{1}\right)}^{0-1}=\vartheta_{(0)}^{1-2} \\
\cline { 2 - 2 } & \varphi_{\left(l_{1}\right)}^{0-1}=\varphi_{(0)}^{1-2} \\
\cline { 2 - 2 } & M_{\left(l_{1}\right)}^{0-1}=M_{(0)}^{1-2} \\
\hline
\end{array}
\end{aligned}
$$

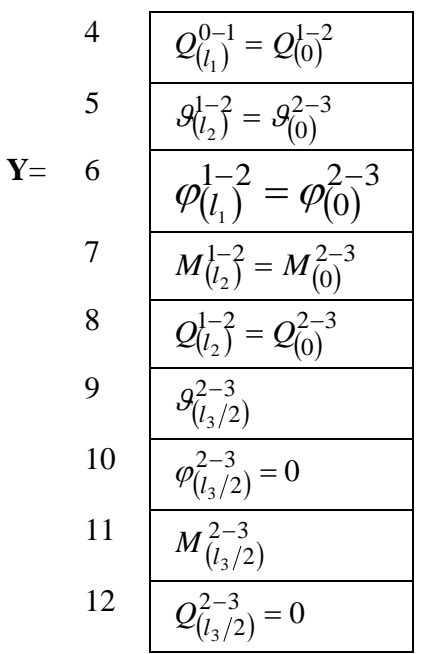

$$
\begin{aligned}
& \mathbf{B}=\begin{array}{|l|}
\hline B_{11}\left(l_{1}\right) / E I_{1} \\
\hline B_{21}\left(l_{1}\right) / E I_{1} \\
\hline-B_{31}\left(l_{1}\right) \\
\hline-B_{41}\left(l_{1}\right) \\
\hline B_{11}\left(l_{2}\right) / E I_{2} \\
\hline B_{21}\left(l_{2}\right) / E I_{2} \\
\hline-B_{31}\left(l_{2}\right) \\
\hline-B_{41}\left(l_{2}\right) \\
\hline B_{11}\left(l_{3} / 2\right) / E I_{3} \\
\hline B_{21}\left(l_{3} / 2\right) / E I_{3} \\
\hline-B_{31}\left(l_{3} / 2\right) \\
\hline-B_{41}\left(l_{3} / 2\right) \\
\hline
\end{array}
\end{aligned}
$$

In this matrix structure, the parameters of vector $\mathbf{Y}$ are completely transferred to the vector of initial parameters. The coefficient matrix A will take the form:

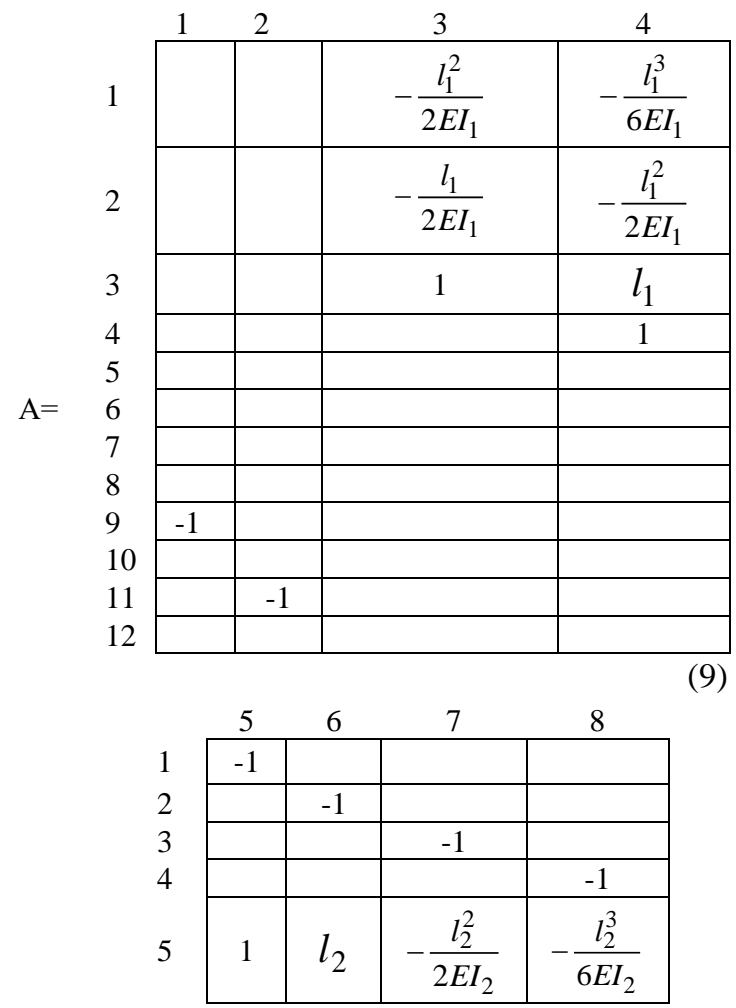


$\mathrm{A}=$

\begin{tabular}{|c|c|c|c|}
\hline 6 & 1 & $-\frac{l_{2}}{2 E I_{2}}$ & $-\frac{l_{2}^{2}}{2 E I_{2}}$ \\
\hline 7 & & 1 & $l_{2}$ \\
\hline 8 & & & 1 \\
\hline 9 & & & \\
\hline 10 & & & \\
\hline 11 & & & \\
\hline 12 & & & \\
\hline
\end{tabular}

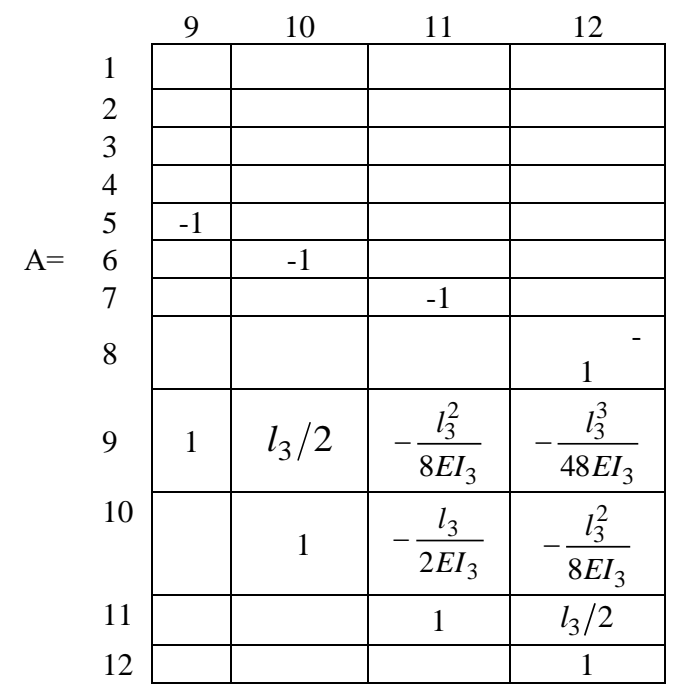

The final resolving equation of the girder bending is written as follows:

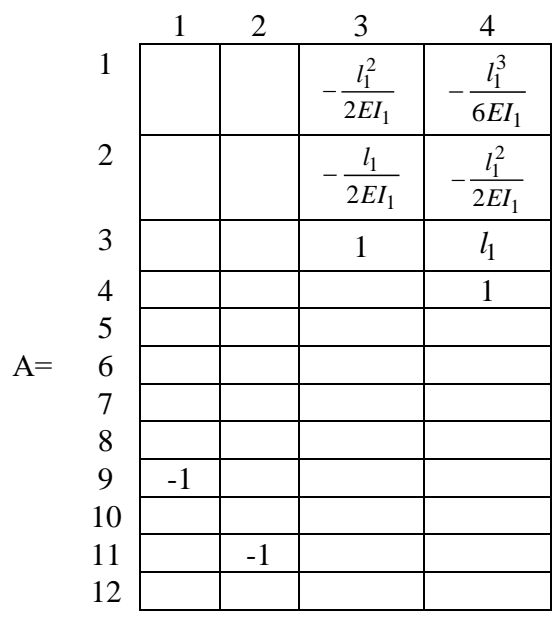

\begin{tabular}{|c|c|c|c|c|}
\hline \multirow[b]{2}{*}{1} & 5 & 6 & 7 & 8 \\
\hline & -1 & & & \\
\hline \multirow{11}{*}{$\mathrm{A}=$} & & -1 & & \\
\hline & & & -1 & \\
\hline & & & & -1 \\
\hline & 1 & $l_{2}$ & $-\frac{l_{2}^{2}}{2 E I_{2}}$ & $-\frac{l_{2}^{3}}{6 E I_{2}}$ \\
\hline & & 1 & $-\frac{l_{2}}{2 E I_{2}}$ & $-\frac{l_{2}^{2}}{2 E I_{2}}$ \\
\hline & & & 1 & $l_{2}$ \\
\hline & & & & 1 \\
\hline & & & & \\
\hline & & & & \\
\hline & & & & \\
\hline & & & & \\
\hline
\end{tabular}

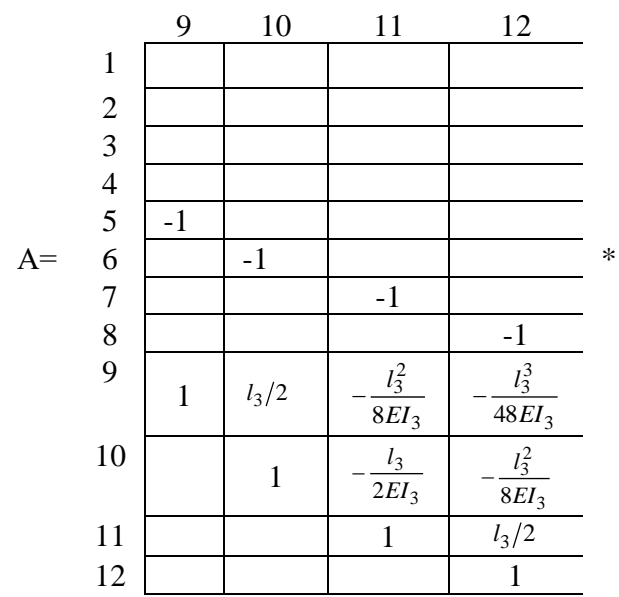

Using the Gaussian elimination method in the MATLAB environment, all the initial parameters of the girder sections can be determined. The calculation of the stress-strain state at the interior points of all sections is performed by calculation according to equation (3). The resolving torsion equation is formed in a similar way. It will take the form:

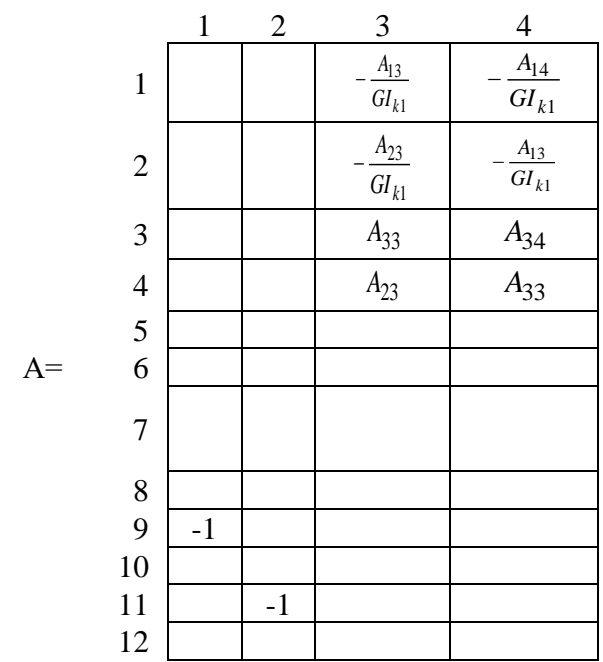




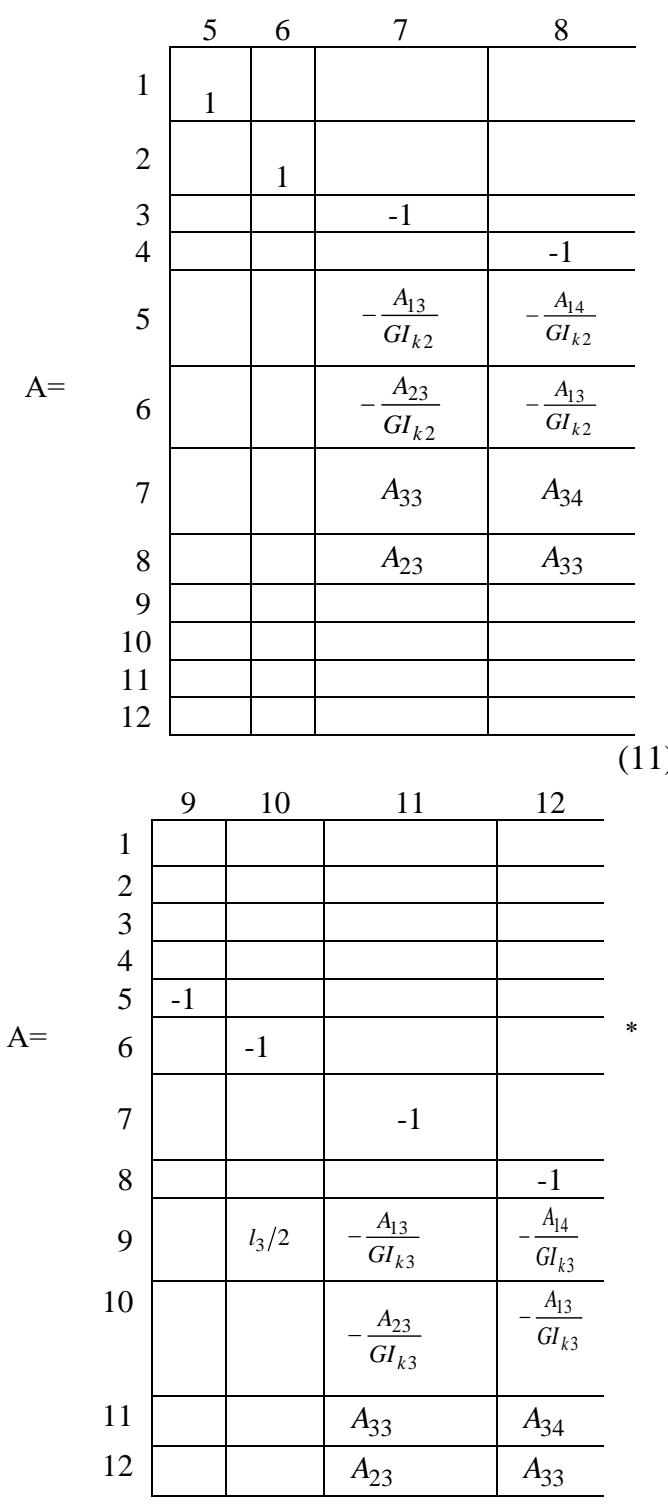

Table 1. Results of calculating the lower girder without thinning of the section walls by the FEM

\begin{tabular}{|r|r|r|r|}
\hline \multicolumn{2}{|c|}{ Research area } & $\begin{array}{r}\text { Stress } \\
\mathrm{MPa}\end{array}$ & $\begin{array}{r}\text { Moving } \\
\mathrm{mm}\end{array}$ \\
\hline \multirow{2}{*}{$\begin{array}{c}\text { Section } \\
\text { without } \\
\text { damage }\end{array}$} & $\begin{array}{r}\text { Upper trans- } \\
\text { verse wall }\end{array}$ & 67,3461 & 0,0764 \\
\cline { 2 - 4 } & $\begin{array}{r}\text { Bottom trans- } \\
\text { verse wall }\end{array}$ & 81,922 & 0,0923 \\
\cline { 2 - 4 } & Vertical wall & 58,675 & 0,0564 \\
\hline
\end{tabular}

\subsection{The resolving equation of the crane by the BEM}

As stated above, the design diagram of the crane is a spatial thin-walled rod system. As a result, each structural element experiences a combined action of bending and torsion. In this case, the kinematic and power parameters of these resistances interact with each other in all nodal sections of structures. For this reason, it is impossible to separately consider the bending and torsional states of the crane. In this regard, for each element of the frame system, it is necessary to combine equations (3), (4) into one. In this case, in addition, it is necessary to take into account the normal forces. The combined equation takes the form:
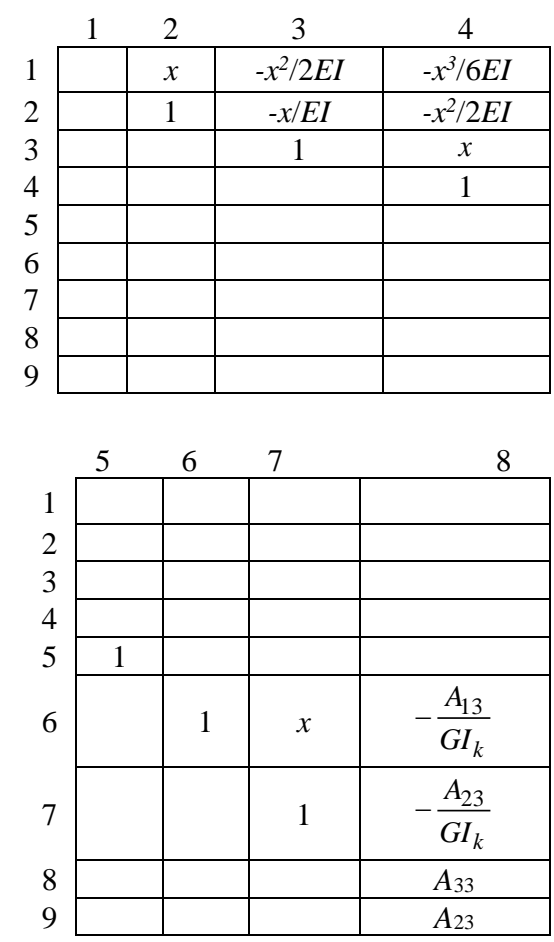

\begin{tabular}{l|l|l|}
\hline$\theta^{2-3}\left(l_{3} / 2\right)$ & & $-B_{11}^{0-1}\left(l_{1}\right) / G I_{k 1}$ \\
\hline$B_{\omega}^{2-3}\left(l_{3} / 2\right)$ & & $-B_{21}^{0-1}\left(l_{1}\right) / G I_{k 1}$ \\
\hline$B_{\omega}^{0-1}(0)$ & & $B_{31}^{0-1}\left(l_{1}\right)$ \\
\hline$M_{\omega}^{0-1}(0)$ & $B_{41}^{0-1}\left(l_{1}\right)$ \\
\hline$\theta^{1-2}(0)$ & $-B_{11}^{1-2}\left(l_{2}\right) / G I_{k 2}$ \\
\hline$\theta^{\prime 1-2}(0)$ & $-B_{21}^{1-2}\left(l_{2}\right) / G I_{k 2}$ \\
\hline$B_{\omega}^{1-2}(0)$ & \\
\hline$M_{\omega}^{1-2}(0)$ & $B_{31}^{1-2}\left(l_{2}\right)$ \\
\hline$\theta^{2-3}(0)$ & $B_{41}^{1-2}\left(l_{2}\right)$ \\
\hline$\theta^{\prime 2-3}(0)$ & $-B_{11}^{2-3}\left(l_{3} / 2\right) / G I_{k 3}$ \\
\hline$B_{\omega}^{2-3}(0)$ & $-B_{21}^{2-3}\left(l_{3} / 2\right) / G I_{k 3}$ \\
\hline$M_{\omega}^{2-3}(0)$ & $B_{31}^{2-3}\left(l_{3} / 2\right)$ \\
\hline & $B_{41}^{2-3}\left(l_{3} / 2\right)$ \\
\hline
\end{tabular}

Calculations of the girder stress-strain state in bending and torsion according to the BEM algorithm are summarized in Table 1.

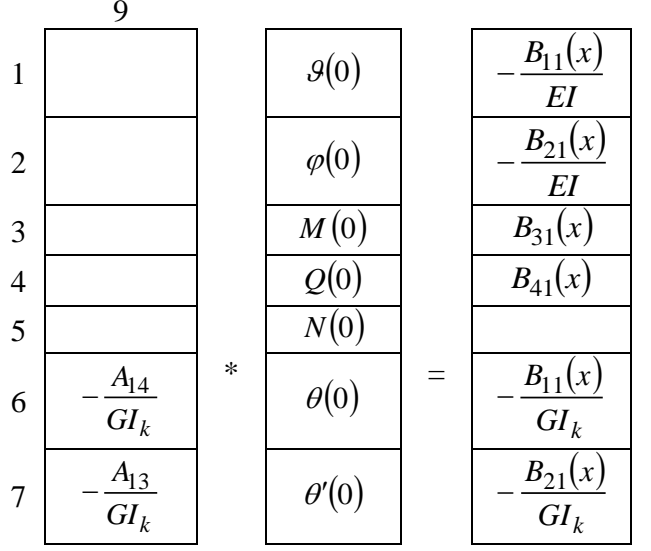




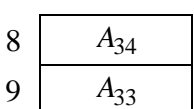

$$
\begin{array}{|c|}
\hline B_{\omega}(0) \\
\hline M_{\omega}(0) \\
\hline
\end{array}
$$$$
\begin{array}{|l|}
\hline B_{31}(x) \\
\hline B_{41}(x) \\
\hline
\end{array}
$$

The general resolving equation for the entire crane by the BEM is formed identically to the above algorithm for the girder. The size of the matrix equation depends on the number of rods in the structure. If there are from 10 to 20 units of these elements, then the matrices will contain 90180 equations respectively. It is very difficult to visually depict such a number of equations. Therefore, the resolving equation for the entire crane is generated automatically bywthe program in the MATLAB environment. All the initial parameters of the crane elements are determined by the Gauss method, and the stress-strain state inside the rods is calculated according to equation (12). The calculation results are presented in Table 2 .

Table 2. Results of calculating the lower girder with thinning of the section walls by the FEM

\begin{tabular}{|r|l|r|r|}
\hline \multicolumn{4}{|c}{ thinning of the section walls by the FEM } \\
\hline \multicolumn{2}{|c|}{ Research area } & $\begin{array}{r}\text { Stress } \\
\text { MPa }\end{array}$ & $\begin{array}{r}\text { Moving } \\
\mathrm{mm}\end{array}$ \\
\hline $\begin{array}{r}\text { Section } \\
\text { with wall }\end{array}$ & Upper wall & 80,81532 & 0,0843 \\
\cline { 2 - 4 } thinning & Lower wall & 98,3064 & 0,1047 \\
\cline { 2 - 4 } & Side wall & 69,438 & 0,0672 \\
\hline
\end{tabular}

\section{COMPARISON OF CALCULATION RESULTS BY THE FEM AND BEM}

Tables 1-3 show the results of calculations of the stress-strain state of the considered section of the gantry lower girder. Figures 2, 3 show a numerical model of the loader and the lower girder with the damaged section. The case of thinning of the walls of the middle section of the loader lower girder is considered. In the design diagram, the load is symmetrical. In real operating conditions, all loading components of the loader are variable under the influence of various factors.

As mentioned above, the most typical types of loads, i.e. bending in the vertical plane and torsion, are considered for the researched design diagram.

Table 3. Comparative calculation analysis by the BEM and FEM

\begin{tabular}{|r|r|r|r|}
\hline \multicolumn{2}{|c|}{ Research area } & \multicolumn{2}{c|}{ Stress } \\
\cline { 2 - 4 } & BEM & FEM \\
\hline \multirow{4}{*}{$\begin{array}{r}\text { Section } \\
\text { without } \\
\text { damage }\end{array}$} & $\begin{array}{r}\text { Upper } \\
\text { wall }\end{array}$ & 64,5 & 67,3461 \\
\cline { 2 - 4 } & $\begin{array}{r}\text { Lower } \\
\text { wall }\end{array}$ & 77,83 & 81,922 \\
\cline { 2 - 4 } & $\begin{array}{r}\text { Side } \\
\text { wall }\end{array}$ & 55,74 & 58,675 \\
\hline \multirow{3}{*}{$\begin{array}{r}\text { Section } \\
\text { with } \\
\text { wall }\end{array}$} & $\begin{array}{r}\text { Upper } \\
\text { wall }\end{array}$ & 76,77 & 80,81532 \\
\cline { 2 - 4 } thinning & $\begin{array}{r}\text { Lower } \\
\text { wall }\end{array}$ & 93,39 & 98,3064 \\
\cline { 2 - 4 } & $\begin{array}{r}\text { Side } \\
\text { wall }\end{array}$ & 65,97 & 69,438 \\
& & & \\
\hline
\end{tabular}

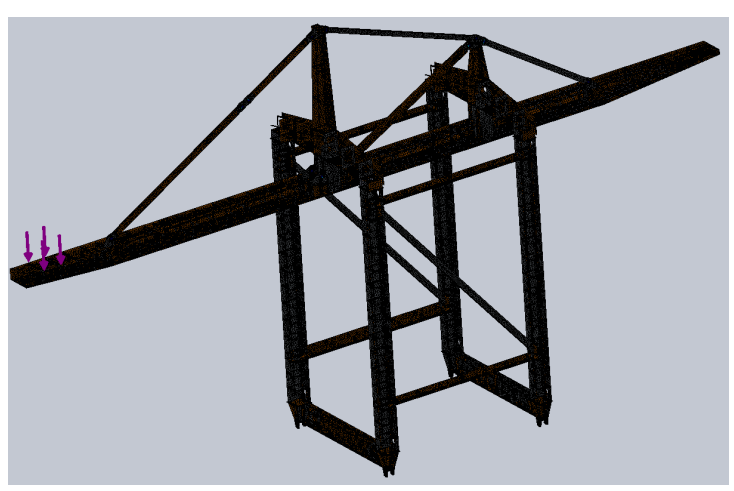

Fig. 2. Numerical model of a container loader

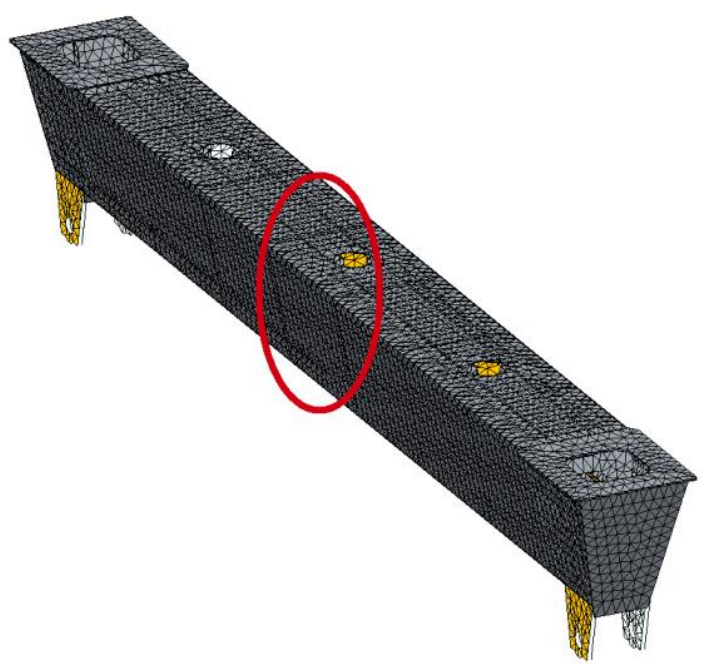

Fig. 3. Numerical model of the lower girder with thinned walls

The values of stresses and strains are presented in tables 1-3. Comparison of the results of calculations by the FEM and BEM is presented in Table 3. As a result of the research, an algorithm for solving problems with a change in the stiffness characteristics of the structural elements of handling equipment was obtained.

\section{DISCUSSION OF THE STUDY OF THE CONSEQUENCES OF THINNING OF THE WALLS OF METAL STRUCTURES}

The results obtained are explained by the correct formulation of assumptions in the modeling and development of design diagrams for metal structures of loaders.

The peculiarities of the proposed approach consist in the use of two different methods for calculating the stress-strain state (by the FEM and BEM), which made it possible to prove the reliability of the calculation results, in contrast to the existing results obtained by other methods of diagnostics of the stress-strain state.

The applied methods, according to the characteristics of the Ansys package and the Matlab environment, do not have any restrictions on the study of the stress-strain state of structures.

The article discusses the process of thinning the 
walls of rod structural elements, which segmentally captures a part of the bearing girder and is the most dangerous case during the operation of loaders.

Taking into account the local thinning of walls of girders is possible only under the conditions of the object two-dimensionality, and here it is necessary to apply the finite element method in various packages for its implementation. It should be noted that the models for the thinning of the girder walls in the finite element method are approximate, in contrast to the boundary element method, where the solutions are exact within the framework of the hypotheses that were adopted when deriving the corresponding differential equations.

In this regard, taking into account the local thinning of walls of girders should be carried out by the finite element method or in a two-dimensional formulation by the boundary element method, and in the case of diagnosing the global thinning of walls of load-bearing structural elements, it is much easier and more accurate to carry out the study by the boundary element method, which is done in the paper.

The applied method of boundary elements has a disadvantage in the form of insufficient realization of the geometry of structures, which differs from the classical design diagrams of rods of plates and shells.

The development of this research may consist in overcoming the difficulties of taking into account the structure geometry different from classical design diagrams.

\section{CONCLUSIONS}

1. The design diagrams of the gantry lower girders have been constructed (Fig. 1-3). For these design diagrams, the matrix equations have been compiled by the BEM. The results of the calculations performed are presented in Tables $1-3$.

2. The analysis of the acting loads on metal structures showed that the most dangerous types of resistance are transverse bending and constrained torsion; shear and tension can be neglected. For these types of resistances, the mathematical models of boundary problems of the lower girders and the entire structure are formed.

3. Having formed the mathematical models of the gantry girders and the entire structure as a whole, using the Matlab programming environment, the results of the study of the stress-strain state by the BEM algorithm were obtained in Table 3.

4. Using the FEM package Ansys in the graphic editor, the finite element model of the lower girders and the entire metal structure as a whole was created, taking into account the thinning of individual sections. This model was calculated using a bar finite element (Beam 189). The calculation results are summarized in Tables 13.

5. The final point of the work is a comparison of the results of calculations by the BEM and FEM. The dangerous sections of girders and elements of metal structures of cranes have been determined, taking into account their thinning. The conclusions on the neutralization of the hazardous state of crane structures are presented.

\section{REFERENCES}

1. Tanchenko AY. The stress-strain state of spatial thinwalled structures taking into account the thinning of the walls of the bearing elements. Bulletin of SevNTU: Mechanics, energy, ecology. 2011; 120: 35-40.

2. Tanchenko AY. Methods for predicting the resource of high-availability subtle elements of machines from ur and huvannya stonshuvannya. 10th Mizhnar. Symposium of mechanics at Lviv. 2011: 34-35.

3. Pettit JR, Walker AE, Lowe MJ. Improved detection of rough defects for ultrasonic nondestructive evaluation inspections based on finite element modeling of elastic wave scattering. IEEE Transactions on Ultrasonics, Ferroelectrics, and Frequency Control. 2015;62(10): 1797-1808. https:// doi . org /10.1109/ tuffe .2015.007140.

4. Lagerev IA. Modeling of the stress-strain state of a manipulator crane of a machine for welding pipelines. Izv. higher. study. institutions. Mechanical engineering 2011; 4: 29-36.

5. Vorona OI. Computer model for the design and construction of non-porous constructions of conveyors. Bulletin of the National University "Lvivska Politechnika. 2009; 641: 17-21.

6. Gubskiy SO. Pre-loaded-deformed mill of metal construction mill for metal construction stand mechanizmu for vantage. Bulletin of the National Technical University "KhPI. Series: Technologies 50 in machine-building 2018; 6 (1282): 50-54.

7. Orobey V, Daschenko O, Kolomiets L, Lymarenko O, Ovcharov Y. Mathematical modeling of the stressed-deformed state of circular arches of specialized cranes. Eastern European Journal of Enterprise Technologies. 2017; 5/8 (89): 4-11.

8. Orobey V, Daschenko O, Kolomiets L, Lymarenko O. Stability of structural elements of special lifting mechanisms in the form of circular arches. Eastern European Journal of Enterprise Technologies 2018; 2/7(92): 4-10. $\quad$ https://doi.org/10.15587/17294061.2018.125490.

9. Orobey V, Nemchuk O, Lymarenko O, Piterska V, Lohinova L. Taking account of the shift and inertia of rotation in problems of diagnostics of the spectra of critical forces mechanical systems. Diagnostyka. 2021;22(1):39-44. http://doi.org/10.29354/diag/132555.

10. Krueger RO, Brien KA. 3D modeling technique for the analysis of deiaminated composite laminates. AIAA Journal. 2000; 37(6): 25-44.

11. Lazareva DV. Finite element analysis of the $\mathrm{n}$ th sheer frame container. Refrigerated technology 2007; 3(107): 77-78.

12. Maksimyuk YV. A finite element of general type for the solution of an axisymmetric problem of non- 
stationary heat conductivity. Opir materialiv i teoriya sporud. 2015; 96: 148-157.

13. Maksymyuk YV. Statement of the problem of the influence of geometric nonlinearity on the bearing capacity and the supercritical behavior of thin-walled and combined axisymmetric bodies. Opir materialiv i teoriia sporud. 2016; 97:186-193.

14. Gulyar OI, Piskunov SO, Maksimyuk YV. Investigation of nonlinear deformation of composite shells of rotation of middle thickness. Tehnichni nauki ta tehnologiyi. 2018; 2(12): 9-24.

15. Bazhenov VA, Saharov OS, Gulyar OI, Piskunov $\mathrm{CO}$, Maksimyuk YV. Peculiarities of using the finite element moment scheme (FEMS) in nonlinear calculations of shells and plates. Opir materialiv i teoriya sporud. 2017; 92: 3-16.

Received 2021-04-26

Accepted 2021-08-16

Available online 2021-08-20

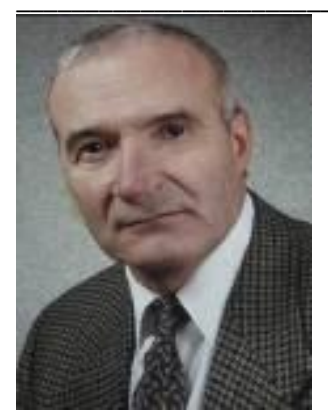

Viktor OROBEY - Doctor of Sciences (Engineering), Professor, Odessa National Polytechnic University, Professor at the the Department of Chair Dynamics, Capacity of Machines and Resistance of Materials, Odessa, Ukraine.
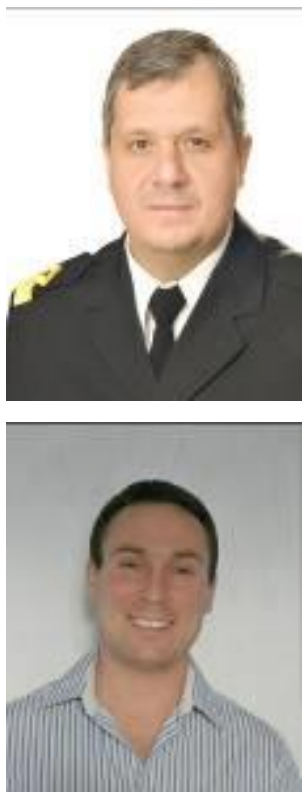

\section{Oleksii NEMCHUK -} Doctor of Sciences (Engineering), Docent, Odessa National Maritime University, Vice-Rector of Science, Odessa, Ukraine.

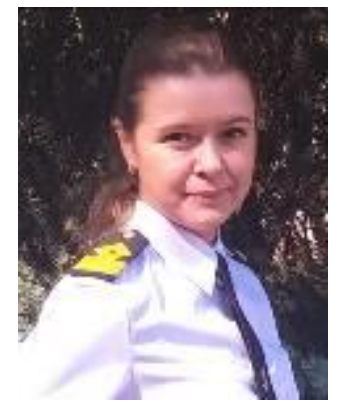

Varvara PITERSKA Doctor of Sciences (Engineering), Professor, Odessa National Maritime University, Professor at the Department of Port Operations and Cargo Works

Technology, Odessa, Ukraine.

Oleksandr LYMARENKO PhD (Engineering), Docent, University, Head of the Department of Chair Dynamics, Capacity of Machines and Resistance of Materials, Odessa, Ukraine.

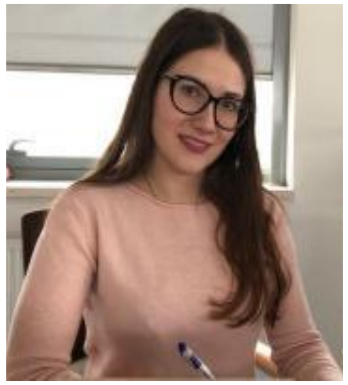

Olha SHERSTIUK - PhD (Engineering), Docent, Odessa National Maritime University, Associate Professor at the Department of Philology, Odessa, Ukraine.

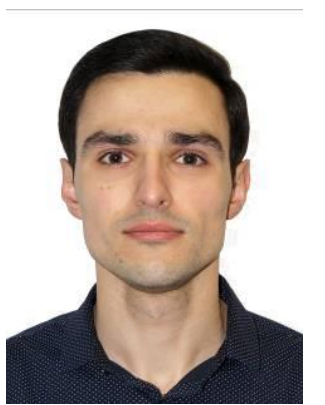

Oleksandr ROMANOV -

Graduate Student of the Department of Dynamics, Capacity of Machines and Resistance of Materials, Odessa National Polytechnic University, Odessa, Ukraine.

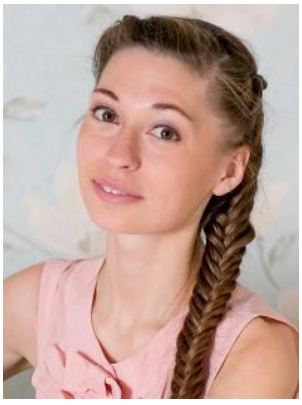

Kateryna TKACHUK - PhD (Engineering), Pryazovskyi State Technical University, Associate Professor at the Department of Liftingtransport machines and equipment, Mariupol, Ukraine. 